ISSN 2236-0859

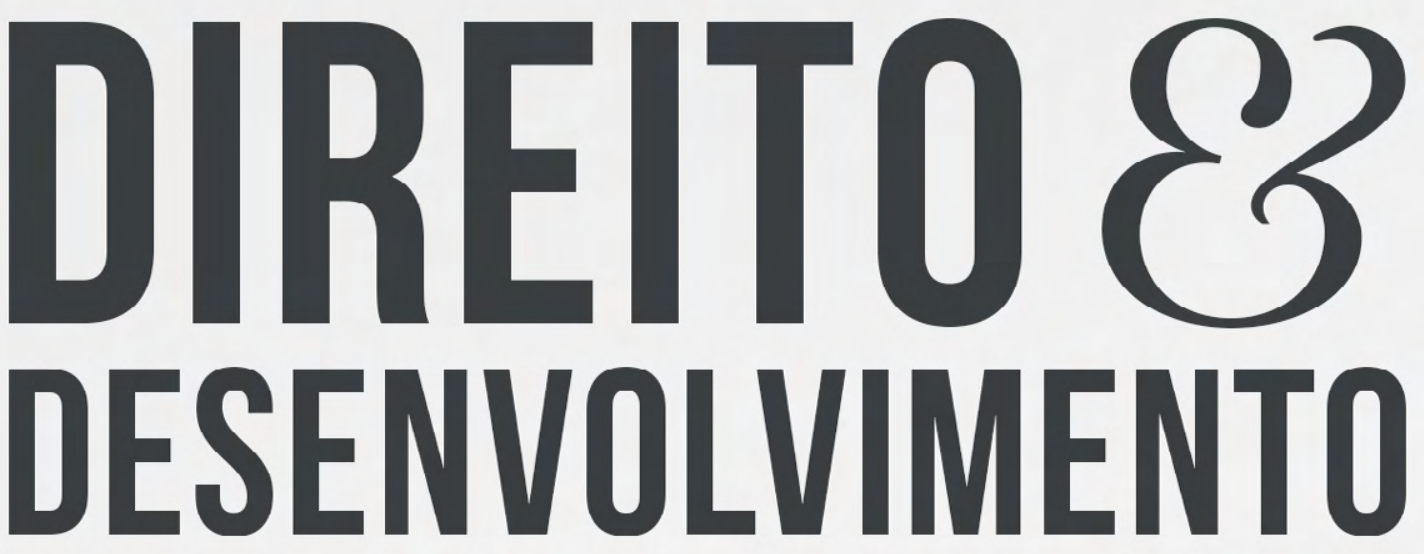

REVISTA DO PROGRAMA DE PÓS-GRADUAÇ̃̃O EM DIREITO MESTRADO EM DIREITO E DESENVOLVIMENTO SUSTENTÁVEL

\title{
AGENCY, CAPABILITIES AND RIGHTS: ACAPABILITIES APPROACH DISCUSSION
}

SÉRGIO FERNANDO FERREIRA DE LIMA

AUGUSTO BONNER COCHRAN

MARCO ANTÔNIO CÉSAR VILLATORE 


\title{
AGENCY, CAPABILITIES AND RIGHTS: A CAPABILITIES APPROACH DISCUSSION
}

\section{AGENCIA, CAPACIDADES E DIREITOS: UMA ABORDAGEM DA TEORIA DAS CAPACIDADES}

Recebido: $17 / 09 / 2018$

Aprovado: 20/10/2018

\author{
Sérgio Fernando Ferreira de Lima* \\ Augusto Bonner Cochran** \\ Marco Antônio César Villatore***
}

\begin{abstract}
The aim of this paper is to show how the concepts of agency, capability, and functioning can be aligned in a way that put in evidence the centrality of individual agency. Usually, discussion about the capabilities approach focuses on the limitations and flaws of the theory; here it will be argued that even with limitations and possible problems the capabilities approach could mean a significant paradigm shift for how we think and make Law and public policies. The method used will to analyze some of the principal texts about the subject and to discuss new elements and perspectives that could be brought to bear on the topic. In the end, the article points to a broader way to use the principles and theory of the capabilities approach to describe and analyze legal theory.
\end{abstract}

Keywords: Capabilities Approach. Agency. Functioning. law.

RESUMO: O objetivo deste artigo é mostrar como os conceitos de agência, capacidade e funcionamento podem ser alinhados de maneira a evidenciar a centralidade da agência individual. Normalmente, a discussão sobre a teoria das capacidades enfoca as limitações e falhas da teoria; aqui será argumentado que, mesmo com limitações e possíveis problemas, a teoria das capacidades pode significar uma mudança de paradigma significativa para a forma como pensamos e fazemos o Direito e as políticas públicas. O método utilizado analisará alguns dos principais textos sobre o assunto e discutirá novos elementos e perspectivas que possam ser abordados sobre o tema. No final, o artigo aponta para uma maneira mais ampla de usar os princípios e a teoria das capacidades para descrever e analisar a teoria jurídica.

Palavras-chave: Abordagem de capacidades. Agência. Funcionamento. Lei.

\section{INTRODUCTION}

The modern world that we live in poses innumerable challenges, especially in the field of enforcement of fundamental and social rights. The capabilities approach can be a novel and efficient perspective for analyzing and describing rights. This article will describe the central arguments of Amartya Sen and Martha Nussbaum about the connection between rights

\footnotetext{
* Mestrando em Direito pela Pontifícia Universidade Católica do Paraná - Brasil; Graduado em Direito pelo Centro Universitário Curitiba (2010); Servidor público estadual, Secretaria de Segurança Pública do Paraná, membro da Complex System Society e da World Complexity Science Academy. E-mail: sergioffernando@gmail.com

**Doutor em Public Policy pela University of North Carolina - Multi-Campus University. Tem experiência na área de Ciência Política. E-mail: gcochran@agnesscott.edu

***Advogado. Pós-Doutor pela Universitá degli Studi di Roma II, “Tor Vergata” (2014). Doutor em Diritto del Lavoro, Sindacale e della Previdenza Sociale - Università degli Studi di Roma, "La Sapienza” (2001), revalidado pela Universidade Federal de Santa Catarina. Mestre em Direito pela Pontifícia Universidade Católica de São Paulo (1998). Professor Titular do Programa de Pós-Graduação em Direito na Pontifícia Universidade Católica do Paraná (PPGD/PUCPR). E-mail: prof.villatore@gmail.com
} 
and capabilities and will review the basic concepts of agency, capabilities, and functioning, linking them through the idea of freedom of choice. A formal description of the law from a top hierarchal position, where national constitutions are the source and the guidelines for the legal system, is the generally accepted view. The typical impact of a given law on the population or of a court decision is frequently the focus of discussions. Usually, we make trade-offs between average benefits and harms in legal disputes, especially in class actions and environmental violations. In all these situations it is easy to lose sight of individual perspective in favor of better or more beneficial overall outputs, i.e., for a large increase in the total well-being.

Much of Sen's efforts present ethical and philosophical challenges to the utilitarian idea of maximizing well-being and self-interest as the sole way to model human behavior. Economic theory has always had a strong influence on legal theory so it is not surprising that much of the legal thinking about rational decision-making in law was based on economic thinking. The challenge to the rational self-interested model of thinking made by Sen, however, must also be taken into account in legal thought.

The objective of this paper is to briefly survey some central concepts of Sen's theory, especially the ideas that led to the formulations of the capabilities approach and his many later formulations. The centrality of the ideas of agency and capabilities are basic building blocks for a space of substantive freedoms, and these concepts offer primary tools for analyses and metrics in the field of fundamental rights. The discussion aims to add more dimensions and elements to a complex and more enriched legal discussion.

Once linked to the concept of agency, the space of freedom of choice, we argue, furnishes a solid foundation for a person-centered theory. In a world where the roles of national states are more and more challenged by supranational influences and global threats the power of individual rights, universally recognized, is increasingly a viable solution, But, before we try to make a global community we must make sure that the most basic needs of each person are adequately fulfilled. The capabilities approach can help to secure a basic set of meaningful opportunities to every person, so we can secure a minimum set of fundamental rights to every citizen.

\section{AGENCY, CHOICE AND FREEDOM}

The work of the Nobel laureate author, Amartya Sen, is known for its impact on the analysis of traditional economic theory through a critique that seeks to reunite the study of ethics with the study of economics (SEN, 1998, P. 1-3), especially through its emphasis on a much broader treatment of concepts such as rationality, choice, and freedom. The concept of individual freedom gains so much relevance in Sen's work that it provides a metric for a better assessment of a country's development, in contrast to traditional metrics based on purely economic elements (such as Gross Domestic Product). (SEN, 1999, p. 24)

A structural description of one central concept for Sen, agency, provides a fruitful starting point for analysis.

The concept of agency it is of crucial importance in Sen's work. In Development as Freedom (1999), Sen says that his use of the term agency is conceived more broadly than in traditional social and economic theories. For Sen, an agent is one who "acts and brings about change" where his actions can be judged in respect of his "own values and objectives". (SEN, 1999, p. 4) Agents have an active role in the society where they are inserted; they actively participate in the public debate. This agency is related to some species of freedoms. Development itself, as a metric, should be evaluated insofar as it effectuates "the removal 
of various types of unfreedoms that leave people with little choice and little opportunity of exercising their reasoned agency." (SEN, 1999).

In his works before Development as Freedom Sen usually uses a pair of concepts to talk about agency, usually: agency and well-being. In 1985 Sen speaks of an aspect of agency as the "moral power to have a conception of the good"(SEN, 1984, p.186) as well as of an aspect of well-being that would be the maximization of self-interest, the standard utilitarian idea of well-being (choice, desire or happiness). (SEN, 1984, p.187)

When we speak of the agency aspect of a person as being the power that allows the formulation of a conception of the good, we are describing a subjective mechanism of value formation and choice of goals that will not always be harmonious with choices that would maximize well-being. Agents are persons who act and cause changes, that is, they choose from the available options of action according to the motivations and objectives internally established. It will not be uncommon to find a situation where agency will require a sacrifice in well-being due to our conceptions of the primary good. Agency functions where agents are in positions to fulfill obligations, even though it may adversely affect well-being (SEN, 2002, p.224) and yet, it will be a rational option for action.

This dichotomy between agency and well-being will be important, for even though it is not absolute, it underlines the fact that it is rationally justifiable to opt for an action other than the maximization of self-interest and well-being as stated by the traditional utilitarian economic theory

This observation is of first importance because it refers to two central criticisms by Sen of utilitarian behavioral theory. In the utilitarian conception, pervasive in economics, agents are holders of preferences, who in the face of options choose from them those that maximize their satisfaction within their set of preferences. According to Cudd, (CUDD, 2014, p. 4) Sen's main criticisms are addressed to the attempt to describe internal motivations through the behavior revealed by choice and the idea that rational behavior must always be self-interested. (SEN, 1984, p.186) The definition of rational choice as the chosen preference that maximizes self-interest and, thus, results in a greater sum of well-being persists despite the model deviating from human reality and regardless of the type of definition or informational basis shaping that view.

It could be argued that economy has produced a set of successful models based on that theory of rationality. Then, it can be said that the economic models always struggle before the reality of the market and are an abstraction of perfect markets and perfect rational agents. The limited success obtained by the traditional economic models were not strong enough to dismiss the modern attempts to make new frameworks for economic theory, more mathematically imperfect, but more realistic and functional. ${ }^{2}$

When we introduce the idea of agency, we start to consider other aspects that are much more complex than those that are used in the traditional modeling of economic and social systems. It is argued that if some kind of description and prediction can be made using the observation of the choice of preferences, this kind of modeling reduces the dimensions of each person to just a few unrealistic elements, moving away from the reality of the market or society. The agency element, in Sen's theory, is enriched by a set of cognitive constructs of preferences, motivations, and goals that we cannot simply access by observing the external choices of any person. This fact adds an enormous factor of uncertainty and complexity to any attempt to model economic and social behavior.

This description can be even more complete and complex with the following illustration given by Sen and commented on by Cudd. In a group of people, each pick from a basket of apples

2 See, e.g. ARTHUR, 2015. 
and mangoes; having the last person picking fruit from a basket that includes one mango is a different choice situation that having the second to last person pick when there is only one mango left. Even if one prefers the mango all other things equal, one might not wish to be greedy or selfish by choosing the last mango and depriving another of that opportunity. This means that social norms provide agents with another source of motivation that the theory needs to be able to capture. (CUDD, 2014, p. o6) In other words, the opaqueness of the external choices are greater than we could expect just by considering a pure and isolated model of rational choice.

The main point that should be highlighted about agency is the centrality of the concept of freedom of choice and the impossibility of obtaining a complete and accurate description of the cognitive process of motivation and formation of goals just by observing the choices that a person makes. On top of that, we cannot assume that this external and visible process of choice is a reflection of a perfect rational internal process.

The assessment made by Sen's theory has brought a new dimension of complexity to behavioral study in economics and social sciences, adding a broad concept of freedom and with it, uncertainty, with its new conceptualization of agency. By placing emphasis on freedom of choices, on preferences and goals formed internally and influenced by formal and informal social norms, we are left with a picture much more nuanced and intricate in observing the doings and beings of persons. Now we should question the nature of these doings and beings.

\section{CAPABILITIES AND FUCNTIONINGS}

What are capabilities? According to Sen capacities refer to combinations of functions that are possible to be attained by individuals: "Capability is thus a kind of freedom: the substantive freedom to achieve alternative functioning combinations (or, less formally put, the freedom to achieve various lifestyles)." (SEN, 1992, p. 40) Nussbaum adds that capabilities are a normally interrelated set of opportunities for choice and action. (NUSSBAUM, 2011, p. 54) The best interpretation of what Sen means by capability is a certain sort of real options or choices open to the person, possible functionings from which a person may choose to do or be. (CROCKER, 2998, p. 174)

The term functioning that appears in the Sen's work refers to the realization of opportunities (capabilities). (NUSSBAUM, 2011, p. 57) Their realization is being or doing something. That means that functionings range from simple things such as "being adequately nourished, being in good health, avoiding escapable morbidity and premature mortality, etc., to more complex achievements such as being happy, having self-respect, taking part in the life of the community, and so on." (SEN, 1992, p. 39) It is possible to say that a function is nothing more than an active realization of a capability. However, this functioning does not necessarily entail being being intrincally active, because being lying comfortably in a park or having health are both functionings.

A capability reflects the alternative combinations of functionings over which a person has the freedom of effective choice. (SEN, 2004, p. 335) It is necessary to stress an important point here: no one has the obligation to take an opportunity or realize a capability. No one has the obligation to do or be something.

Since functioning is understood as the realization of capabilities, which in turn are the expression of substantive freedom of choice, that leads us to the initial concept of agency; once we are back to agency, we are in a space of freedoms, including the freedom to not choose anything at all. The space of individual free agency is paramount at any given time or situation. 
From this perspective, two people can have the same set of capabilities and choose different functionings or have different sets of capabilities and the same kind of functioning. (SEN, 1990, p. 116)

Applying these elements of the concept of capabilities in a large framework is what was called the capability approach. The capability approach, had its first draft in the paper "Equality of what?" (1982) where Sen asks about metrics of equality. (SEN, 1980) The approach is born as a person-centered approach that puts human agency in the center of attention rather than the market, governments or other types of organizations. (DREZE; SEN, 2002, p.6) The capability approach aims to capture the fact that two persons can have very different substantial opportunities even when they have exactly the same set of external tools. A people who had some kind of disability can do a lot less than a person with no disability if both have the same income and access to same primary goods. The point of view of capabilities asks what actual opportunities individuals have, not the means at their disposal to command. (SEN, 2004, p. 332)

The paradigm shift here is significant because one is no longer concerned with a better way to model and compare markets, government structures or social models from a top-down fashion. With the concepts developed by Sen, it is possible to think of an economic and social organization that must be founded on individuals and their exercise of their free agency, realizing the opportunities available to them. After all, choosing should itself be a valuable part of living, and a life abundant with genuine choice among meaningful options should be seen to be a much richer life to be lived. (SEN, 1992, p. 41)

Possibly the author who most developed the concept sketched by Sen's idea of a capability approach is Martha Nussbaum. In Nussbaum's formulation, it is possible to identify new elements that allow better description and easier understanding and applications of the capabilities structure.

The fundamental distinction made by Nussbaum is about the so-called internal capabilities and combined capabilities. Internal capabilities are skills trained or developed, in most cases, through social, political and economic interaction. A typical example is the abilities developed through contact with the governmental education system, although these internal capabilities may interact and act simultaneously with the combined capabilities, they have different functions. (NUSSBAUM, 2011, p. 51)

The combined capabilities are defined as internal capabilities plus social, economic and political conditions where the functioning can be effectively chosen. As such, it would not be possible to imagine a country that failed to encourage the development of internal capabilities but expanded combined capabilities. However, it would not be difficult to imagine a country that develops external conditions for real opportunities but fails to promote the development of internal capabilities for part of the population, making it impossible for this group to effectively realize its capabilities in functions. This is particularly visible in countries where the poor do not have any access to or have only precarious access to education and health care, while the portion of the population that can afford quality services benefits from economic and social opportunities encouraged by the government. (NUSSBAUM, 2011, p. 52)

This distinction is critical once we adopt the capabilities approach as an account for basic social justice, as Nussbaum did. For example, we may be faced with a country where the authoritarian regime violently represses any kind of demonstration against the government, so that the ability to critically discuss the political situation (internal capabilities) can never be realized in external functioning. Also, we may face a social situation where paid employment for women is not acceptable, making the acquired abilities (internal capabilities) not achievable if the agent is a woman. In both cases, even if the government offers educational structures 
that allow the formation of these internal capabilities if the economic and social conditions do not allow the externalization of these internal capabilities into real functioning, there is no real freedom of choice and we face a grave impairment of free agency.

It is important to promote and expand capabilities because they are ways to achieve functionings. The functionings are the endpoints of the capabilities. This is the foundation of creating meaningful opportunities for citizens, not just the creation of any formal opportunities. Moreover, it is never too much to stress that capabilities have value in themselves as a space of freedom and choice, even though this space never forces anyone to function in a specific way. (NUSSBAUM, 2011, p. 58)

Perhaps, one of the most important achievements of the capabilities approach is to show poverty as a deprivation of capabilities rather than just economic shortcomings. (HICK, 2012, p. 3)

In this way, we can say that the capabilities approach is based on the ideas of individual freedom of choice and the dignity of human beings. However, these conditions are naturally vulnerable. Elements and conditions external to individuals and beyond their control play a key role in determining the capabilities available in a society. In this way, governments are central, and the government is responsible for ensuring that citizens have the necessary access to the central capabilities for a decent life. (NUSSBAUM, 2007, p. 11)

\section{CAPABILITIES APPROACH AND RIGHTS}

In the previous section dealing with the concept of capabilities and its formulations, capabilities were used at various times side by side with individual rights. In this section this possibility, implicit in the discussion above, will be better explored.

The first step will be Sen's position about the use of capabilities to understand and ground human rights. In his 2005 paper, "Human Rights and Capabilities," Sen begins with the following questions: Could human rights be seen as entitlements to certain basic capabilities? Would this be an advantageous way of thinking about human rights? Since human rights require specificity, does the use of the capabilities perspective require a finite list of capabilities? And finally, how can we affirm the content of basic capabilities when our values are supposedly divergent, especially across various national cultures and borders? (SEN, 2005, p. 152)

It could be said that human rights can be seen as rights to certain specific freedoms; in this way we can consider human rights entitlements as an obligation to safeguard and expand those freedoms. As capabilities can be seen as freedoms of a specific type (freedom of choice) we could establish a relationship between human rights and capabilities. However, Sen points out, there is a weak link in our relation, the dual aspect of freedoms: opportunities and process. The opportunity aspect of freedom its related to effective freedom, linked with the opportunity we have to achieve things we see as valuable. The process aspect relates to the importance of the process of autonomous choice and non-interference from others. (PRENDERGAST, 2005, p. 1153) While capabilities seem to adequately encompass the opportunity aspect of freedoms, the same does not seem to happen with the process aspect of freedoms. (SEN, 2005, p. 152)

This point can be illustrated as follows: we know that provided symmetrical health care, women tend to live longer than men. Now, it can be argued that from the pure point of view of equality of capabilities to live longer, more resources and attention should be given to the health of men than to women, even at the cost of a flagrant violation of the right of equal access to health, or that is, equality in process. It can be said, then, that in this case, the need for equality in the process clearly overrides the need for equality in capabilities. Thus, 
even though it is relevant to use the capabilities approach to evaluate the real opportunities available to people, this aspect cannot conflict with the process aspect of freedoms, if we are interested in a theory of justice or social choice. (SEN, 2005, p. 156)

The fundamental question about the creation of a list of capabilities, says Sen, is how would the election of these universally shared basic capabilities be made? As careful as we could be to select them, at the exact moment the list it is created, we are creating a hierarchy of capabilities. Even if the contrary is expressly stated, the mere existence of such a list will be enough to make the capabilities included more important than all others. And we still have the problem of how to evaluate their validity for different cultural, social, and economic contexts? To address this problem, we would have to go through public discussions and reasoning, unfortunately not just locally, but among various localities and cultures, a task that is not doable in a simple way. (SEN, 2005, p. 157-162)

In the end, human rights and capabilities are two concepts that can be developed well side by side; however, one must be careful not to try to completely encompass one concept in the other, says Sen in his 2005 paper. The capabilities approach is a fantastic complement to the opportunity aspect of freedoms of the human rights, but it will not be sufficient to deal with the process aspect of these rights that is necessary for an idea of justice and social choice. (SEN, 2005, p. 163)

Acknowledging as an initial point Sen's assumptions about capabilities, Nussbaum goes beyond the restrictions placed on its use in connection with human rights and creates a list of basic capabilities and guidelines for its use. In this version of the capabilities approach, Nussbaum wants not only to address the problems raised by Sen but, while doing so, she creates a framework for legal analysis not only for national constitutions but also for public management and lawmaking.

In the firsts pages of her book Creating Capabilities, Nussbaum warns that its formulation should be called Capabilities Approach, always in the plural, to emphasize that the most important capabilities in a person's life are always plural and qualitatively distinct and cannot be reduced to a single metric without distortions.(NUSSBAUM, 2011, p.45) It is important to note, that Nussbaum, unlike Sen, will say that her formulation will be specifically concerned with social justice. (NUSSBAUM, 2011, p.47) In this formulation of the capabilities approach we will start with the questions: What can people be and do? Are these beings and doings real, or are there some kind of impediments to them? (NUSSBAUM, 2007, p. 5)

The capabilities approach can be defined as a formulation for a comparative description of the quality of life and theorizing about basic social justice, not just in an abstract way but also being responsive to the world and its problems. (NUSSBAUM, 2006, p.1) Asking what each person can be and do means taking people individually as an end and assessing the opportunities available to each one and not just as an aggregate or average percentage of persons. This approach asserts that the role of government, in any society, is to promote and secure a set of core opportunities (substantive freedoms) that people can or cannot actively use in functioning. The choice remains theirs, and theirs alone. The importance of freedom of choice and self-determination is central. Finally, the approach is concerned with social justice and inequality, especially marginalization and discrimination. (NUSSBAUM, 2011, p. 47)

The creation of a list of basic or central capabilities is justified because this version of capabilities approach focuses on such a central area of freedom whose removal would make life empty of human dignity. The capabilities approach does not concern itself with all types

3 About the concept of dignity Nussbaum says that "dignity is a vague idea that needs to be given content by placing it in a network of related notions, it does make a difference. A focus on dignity is quite different, for example, from a focus on satisfaction" "NUSSBAUM, 2011, p.66". Some pages ahead she added: "The notion of dignity is closely related to the idea of active striving. It is thus a close relative of the notion of basic capability, something inherent in the person that exerts a claim that it should be developed." (NUSSBAUM, 2011, p.68). 
of freedom, but only with this core freedoms, so central that there is a supranational consensus on its importance, such as the importance of primary and secondary education. (NUSSBAUM, 2011, p.69)

At this point, Nussbaum's formulation departs radically from Sen. For while Sen elaborates in detail his own theory and applications for capabilities, he does not describe how they should effectively be used for public policy formation or legal and legislative control. Nussbaum's formulation, however, does just that. In doing so she takes a step forward in comparing capabilities and rights.

According to Nussbaum, we could think of rights as combined capabilities to functions in several ways. Since, combined capabilities are internal capabilities plus social and economic external opportunities our description of rights, automatically, has a double dimension. The right to freedom of expression or political participation can be thought of as human capabilities to functionings.

Citizen who are denied access to information cannot properly form their conception of religion in order to exercise their religious freedom, no matter what variety and degree of formal religious freedom the government offers. In this way, a better description and evaluation of the right to freedom of religion would be achieved by seeing it as combined capabilities. In this sense, it is possible to say that the combined capabilities are the goals of public planning. (NUSSBAUM, 1997, p. 291) Another important reason for describing rights as capabilities is the perspective provided that allows us to understand that securing a right requires more than simply having it written on paper. Thinking of rights as capabilities provides us with a framework for how to think about what and how to secure that right to someone in a meaningful way. (NUSSBAUM, 1997, p. 294)

From that perspective, this approach is not about a passive role of the government; instead, it demands active participation in the promotion and protection of this central set of capabilities. In that way, a key role of national constitutions and legal traditions that interpret them is to ensure to all citizens this central set of capabilities in fields of primary importance to human life. (NUSSBAUM, 2007, p. 7)

At this point, it could be argued that the view of rights as capabilities is not adequate to deal with property rights, or the distribution of economic resources, for example, since an equal distribution of these resources would be unthinkable. The opposite is true, says Nussbaum, because the capabilities approach, in this case, would highlight the fact that the same amount of resources for people with a very large capability disparity will return completely different results. In this view, the question proposed by the capabilities approach in the beginning still holds: what are people really capable of being and doing with the given amount of resources? In this way, we can understand more deeply individual positions and guarantee these rights in a way that they are not mere words on paper. (NUSSBAUM, 1997, p. 295) The question still remains about the process aspect of freedom, that Sen argued it was not covered adequately by the concept of capabilities. We argue that Nussbaum responds that problem by giving her list of basic capabilities and a kind of guiding principles for its interpretation.

\section{BASIC CAPABILITIES AND LAW}

Considering the various areas of human life in which people move and act, what this approach to social justice asks is: what does a life worthy of human dignity require? The answer will be, at a bare minimum, a sufficient threshold level of ten Central Capabilities: (NUSSBAUM, 1997, p. 287-288) 
Life (1). Here we can find all sorts of capabilities linked with life span; (2) Bodily Health: the capabilities related to a healthy life in all dimensions; (3) Bodily integrity: the capabilities linked with the body freedoms and protections against violence. (4) Senses, Imaginations and thought: the large array of capabilities related to intellectual development, expression and protection; (5) Emotions: all the capabilities that represent emotional functionings and support them; (6) Practical reason: the capabilities that allow the formation of a conception of good and critical thinking; (7) Affiliation: with others human beings (A) and protection from harm while in contact with others, the non-humiliation principle (B); (8) Other species: capabilities related to other species apart from human beings; (9) Play: the recreational capabilities; (10) Control over one's environment: the capabilities to effective participation in the public debate and reasoning (A), and the capabilities that allow control required for economic opportunities and that prevent interference with private property (B).

Every government should provide a minimum threshold of these ten basic capabilities for all its citizens. This is not a final and definitive list. It can always be questioned and redone. It must be specified in the face of concrete local needs by the use and interpretation of local constitutions. (NUSSBAUM, 1997, p. 286)

Following the list of basic capabilities, Nussbaum assigns eight guidelines for her formulation of the Capabilities Approach: (1) Entitlement, not Charity. Capabilities (real opportunities) are the right of each and every citizen, and all citizens have equal rights in the specified areas; (2) Combined Capability, not Notional Freedom: the opportunities and choices must be real; people must be able to really select the activity in question. All capabilities require state action for their support; benign neglect is not enough; (3) Capability, not Satisfaction of Desire. The capabilities approach is about what people are actually able to do and be, not whether their desires are satisfied; (4) Each Person an End. We are not interested in the overall good in any way that violates the entitlement of each citizen; (5) Plural and Noncommensurable Opportunities. The capabilities (opportunities) are not simply quantities of some indifferent value: they are distinct, plural, and different in quality. In that way, one cannot satisfy one entitlement by giving people a very large amount of another; (6) Centrality of Choice. The focus is capabilities, because respect for people's power of choice is at the center of the entire approach; (7) Special Role of Education. The main point of the capabilities approach it is to form people able to really choose and think critically. (8) Need for Imagination. The necessity to put himself in another's shoes through imagination is a quality required for each policymaker and lawmaker that works with the capabilities approach. (NUSSBAUM, 2007, p.13-15)

Once we have the core capabilities list and the guidelines, we can address the problems raised by Sen in his lecture about rights and capabilities. For instance, it should be noted that the objective of the capabilities approach will be focused on capabilities, not the actual functions actively used by persons (Centrality of Choice). The role of government, as viewed by the capabilities approach, is to ensure that people have meaningful choices that they value. The decision whether to choose that opportunity, however, is left entirely to the person. Capabilities mean opportunities for choice. That is, the notion of freedom is embedded in the idea of capabilities. (NUSSBAUM, 2011, p. 57) Respect for individual dignity requires that these opportunities are not forced on people, no matter how significant they appear. Thus, e.g., owning real political rights does not mean the obligation to participate in the political life of your country. (NUSSBAUM, 2007, p.12)

But it is not only necessary to offer opportunities to develop internal and combined capabilities or to encourage functionings; it is necessary that a minimum of doings and beings be attained by people (Combined Capability, not Notional Freedom). This point is called by Nussbaum of a minimum threshold of capabilities. (NUSSBAUM, 2007, p.12) This idea will 
become important when assessing the limits and goals for government; the lawmakers and public managers should try to get people past a minimum threshold of effective capabilities. (CROCKER, 2008, p. 32).

This threshold level of combined capabilities that a nation should pursue for all citizens is not a coerced functioning (Centrality of Choice) but a level of substantial freedom to choose and to act. (NUSSBAUM, 2001, p.56) This threshold must be defined through public debate, as pointed out by Sen, but there is no doubt that some capabilities have a universally accepted minimum threshold, below which there will be a breach of entitlement of that capability(NUSSBAUM, 1997, p.77) and an unenforced right.

In addition, the capabilities approach states that although all capabilities are connected, it is not possible to enhance one capability as a compensation for the neglect of another. (NUSSBAUM, 2007, p.13) The capabilities have different qualities and cannot be the objects of simple tradeoffs.

These capabilities are irreducible and heterogeneous. It is not possible for a government to satisfy one of them by over-promoting another, or simply by providing money. (Plural and Noncommensurable Opportunities).

The satisfaction of the specificity of these basic capabilities will be accomplished through the elected protection of the fundamental rights in each local constitution. (NUSSBAUM, 2011, p.76) In that way, we can lessen the effect of a list of capabilities. The local Constitution should be the public forum of discussion and reasoning to select the fundamental rights that can mirror the set of core capabilities. But the non-commutability of the capabilities (Plural and Noncommensurable Opportunities) makes it much harder to balance and create social and economic opportunities. In another way, that same property secures more solidity for rights and compels the government to take effective actions to promote and expand real capabilities.

This version of the capabilities approach diverges in many ways from that sketched by Sen, and we must always keep in mind its differences and the resources employed by Nussbaum to bypass Sen's criticisms of this type of work. However, it seems that its use in law and public administration is fertile and represents a real attempt at a theory of choice and social justice.

If we take the capabilities approach, as formulated by Nussbaum, and use it for legal analyses what kind of new perspectives could we find?

Firstly, we will have a framework for scrutiny and measurement of the effectiveness of the fundamental and social rights, selected in the constitution, once we describe them as capabilities. Is it possible to better solve the problems of conflict and hierarchy of fundamental rights in that way? Could we better design public policies and administrative process once we take into account the double dimension of capabilities as rights?

Secondly, we started with the concept of agency, not by chance. The person-centered perspective on capabilities is fundamental in Sen's work and it could be an important turning point for many legal discussions. It moves the focus from the national state or political organization to the individual citizen and how the relations of people's freedoms and choices can change and give birth to social organization. It is a bottom-up approach to social organization.

Thirdly, Nussbaum, looking to solve the problems raised by Sen for capabilities as human rights, created a system of balances and rules that brought many interesting questions to light. (NUSSBAUM, 2007, p. 14-15) The very idea of combined capabilities, for example, makes it almost impossible to think in terms of purely negative rights, because, every capability, every single fundamental right linked with a basic capability, will require action for its fulfillment. (NUSSBAUM, 2007, p. 21) 
It is possible to combine the list of core capabilities and the guidelines and apply it in critical analyses of courts' decisions. (NUSSBAUM, 2007, p.7) Ideas like Centrality of Choice and Each Person an End could be applied in many forms to construct public policies very different from what we currently have in any area.

The capabilities approach, as formulated by Nussbaum, can provide a range of tools for creating new perspectives to think about fundamental rights and social justice. Its focus on agency and individual freedom of choice could be a touchstone for a more realistic and flexible interpretation of the law and its application in a more efficient and meaningful way.

\section{FINAL CONSIDERATIONS}

For a long time, legal theory survived with few changes in most countries. Law, in general, has a high threshold of resilience. Nonetheless, the society keeps changing and the gap between societies and their legal systems are greater every year. It is a necessity to bring forward new perspectives and to try new solutions. In the same spirit that Sen asked for a reintroduction of ethics in economics, we should ask for a reintroduction of many elements that law left behind in its path. The perspective of reintroducing persons, citizens, as the primary elements of law is relevant. The notions of imperfect previsions, non-self-interested behavior, non-commutability of capabilities (rights), centrality of freedom of choice, are the tools for a more objective control of efficiency for the enforcement of fundamental rights in the constitutions.

The possibilities for applications in law of the capabilities approach theory are many, some of which were highlighted in this paper, and it should be the object of more and more tinkering and exploration by legal researchers. It can be argued, for example, that if all rights are in some way positive rights, as long we think of them as combined capabilities, then tax law is essential to the expansion of capabilities and for the accomplishment of fundamental rights. ${ }^{4}$ So, a rethinking of the objectives and structure of the tax law could be attempted, in that light. In the field of public policy, it could change the way the public programs and process are configured so that the external dimension of the capabilities could be matched more easily with the internal capabilities, assuring a minimum attrition of dragooning opportunities and choices to people.

The way of thinking capabilities as a network of interdependent and heterogeneous elements could lead to a model for thinking about rights in a more organic way, providing more flexible solutions. In any case, it is necessary to think about fundamental rights, their expansion and protection, through new lenses and with new tools. The capabilities approach seems to provide exactly the right type of elements for that new perspective, the time seems to be ripe for that kind of undertaking.

\section{REFERENCES}

ARTHUR, Brian. W. Complexity and the Economy. New York: Oxford University Press, 2015.

CROCKER, D. Agency, functioning, and capability. In Ethics of Global Development: Agency, Capability, and Deliberative Democracy, p. 150-184. Cambridge: Cambridge University Press, 2008.

4 Following the argument in HOLMES, S.; SUSTEIN, C.R. The Cost of Rights: why liberties depend on Taxes. Norton and Company: New York, 1999. 
CUDD, A. Commitment as motivation: Amartya Sen's theory of agency and the explanation of behaviour. Economics and Philosophy, n. 30, v.1, 2014.

DREZE, J.; SEN, A. India: Development and Participation, New York: Oxford University Press, 2002.

HICK, R. The Capability Approach: Insights for a New Poverty Focus. Journal of Social Policy, 41(2), 291-308, 2012.

HOLMES, S.; SUSTEIN, C. R. The Cost of Rights: why liberties depend on Taxes. New York: Norton and Company, 1999.

NUSSBAUM, M. Capabilities and Human Rights, FORDHAM Law REVIEW. v.66, n. 2, 1997.

Constitution and Capabilities: Perception Against Loft Formalism. Harvard Law Review, n.1, v. 121, nov. 2007.

Creating Capabilities: The Human Development Approach. Cambridge: Harvard University Press, 2011.

Frontiers of Justice: disability, nationality, species membership. London: Belknap press, 2006.

PRENDERGAST, R. The concept of freedom and its relation to economic development-a critical appreciation of the work of Amartya Sen, Cambridge Journal of Economics, v. 29, 2005 .

SEN, Amartya. Development as Freedom, New York: Oxford University Press, 1999.

. "Well-Being, Agency, and Freedom: The Dewey Lectures 1984," Journal of Philosophy, v. 82, n. 4, April, p. 169-221, 1984.

Inequality Reexamined, New York: Oxford University Press, 1992.

Justice: Means versus Freedoms. Philosophy and Public Affairs, n. 19, 1990.

On Ethics and Economics. Oxford: Blackwell, 1988.

. Rationality and Freedom, Harvard University Press: Cambridge, 2002.

Equality of What? Tanner Lectures on Human Values. Salt Lake City: University of Utah Press, p. 196-220. 1980.

Human Rights and Capabilities, Journal of Human Development, v. 6, n. 2, Jul. 2005 .

Elements of a Theory of Human Rights, Philosophy and Public Affairs; Fall, n. 32, v. 4,2004 . 